\title{
Structure Design and Simulation Analysis for Concrete Arch Dam of Hongyan Hydropower Station
}

\author{
Xie Xiangzan \\ Hunan Urban Construction College \\ Xiangtan, China \\ 42831966@qq.com
}

\begin{abstract}
Hongyan hydropower station is located in Maotiao river, in Xiuwen county of Guizhou province, it is a power generation project and designed the third class structures, Pivotal Project are composed of dam, water diversion tunnel, powerhouse, subsidiary dam, etc. Dam is concrete double curvature arch dam. Valley is narrow where dam site is located, V-shaped, and provides good terrain for dam construction. The stress and strain of arch dam structure not only are the index of arch dam structure rigidity, but also are the basis of identifying whether the arch dam structural damage occur. Horizontal section and vertical section of double curvature arch dam are all curve shaped, it is the most representative in the arch dam type. This paper adopts the universal finite element calculating software to design and simulate double curvature arch dam of hongyan hydropower station, and gives stress and deformation distribution of arch dam during construction and operation period. Analysis results can provides certain theoretical basis for structure design and construction of double curvature arch dam.
\end{abstract}

Keywords-Hongyan hydropower station; Concrete arch dam; Structure design; Simulation analysis; Stress distribution

\section{INTRODUCTION}

Hongyan hydropower station is located in Maotiao river, in Xiuwen county of Guizhou province, dam site is $80 \mathrm{~km}$ distance from Guiyang city, with a control area of $57093 \mathrm{~km}^{2}$, it is a power generation project and designed the third class structures[1]. Design flood level of reservoir is $54 \mathrm{~m}$, corresponding to downstream water level is $6 \mathrm{~m}$; check flood level is $58.75 \mathrm{~m}$, corresponding to downstream water level is $11 \mathrm{~m}$. Pivotal Project are composed of dam, water diversion tunnel, powerhouse, subsidiary dam, etc[2]. Dam is concrete double curvature arch dam, maximum height of dam is $60 \mathrm{~m}$, thickness at the bottom of dam is $9.03 \mathrm{~m}$, thickness-height ratio of arch dam section is 0.15 , arc length of dam crest is $132.65 \mathrm{~m}$, largest central angle is 116 。 , concrete strength grade of arch dam is C20. Valley is narrow where dam site is located, width of river is 25 to $30 \mathrm{~m}$, ratio of width to height is 2.21 , $\mathrm{V}$-shaped, and provides good terrain for dam construction[3].

\section{CALCULATION MODEL}

\section{A Model Parameters.}

Concrete strength grade of concrete arch dam of Hongyan hydropower station is C20, elastic modulus of concrete is $25.5 \mathrm{GPa}$, poisson's ratio of concrete is 0.167 [4-5], bulk density is $24 \mathrm{kN} / \mathrm{m}^{3}$. Rock layer in the dam site is cambrian dolomite, elastic modulus of concrete is $20 \mathrm{GPa}[6]$, poisson's ratio of concrete is 0.28 .

\section{B Model Elements.}

Concrete arch dam and the bedrock structure are simulated by using eight node isoparametric brick element, the element with 8 nodes is used in the $3 \mathrm{~d}$ model of the entity structure, each node of which has three translational degrees of freedom, and have the characteristics of plasticity, creep, expansion, stress stiffening, large deformation, large strain, etc[7-8].

\section{Model Size.}

Size of calculation model is $200 \mathrm{~m}$ along the flow direction, $200 \mathrm{~m}$ at the transverse that is perpendicular to the flow of water, $205 \mathrm{~m}$ at the vertical that is perpendicular to the flow of water, simulation range is $200 \mathrm{~m} \times 200 \mathrm{~m} \times 205 \mathrm{~m}$. Finite element calculation model of arch dam and bedrock shows in Fig.1. 


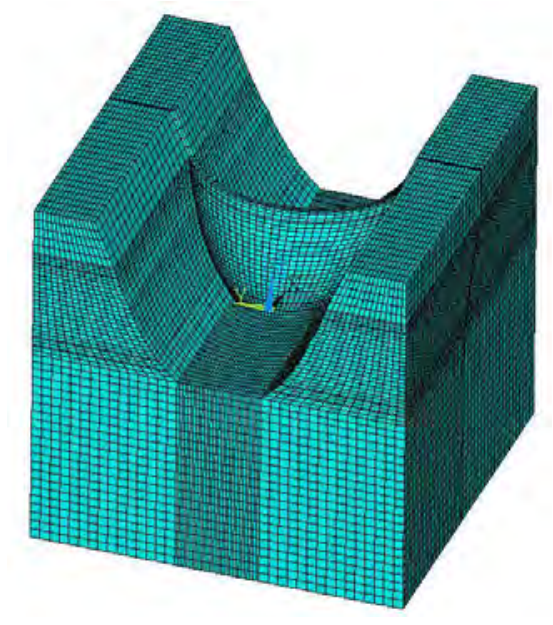

Figure 1. Finite element calculation model of arch dam and bedrock

\section{Calculation Cases.}

Based on mechanical characteristics of arch dam during operation period[9], mainly consider the following 4 kinds of calculation cases: case 1, dead weight; case 2, dead weight and design water level and tail water level; case 3, dead weight and check water
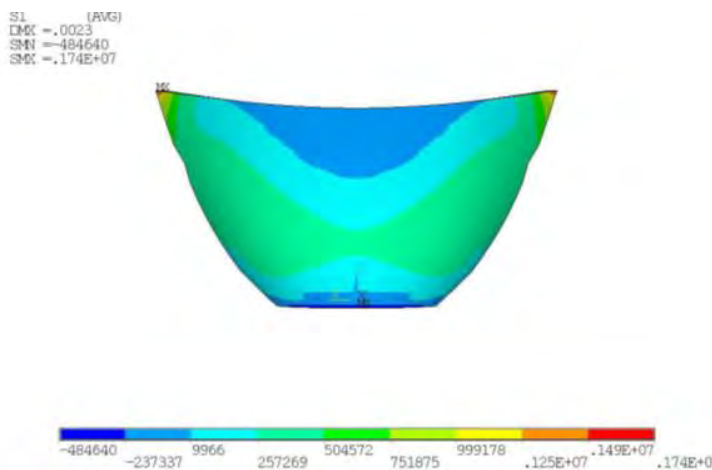

Figure 2. The first principal stress nephogram of arch dam under case $1(\mathrm{~Pa})$
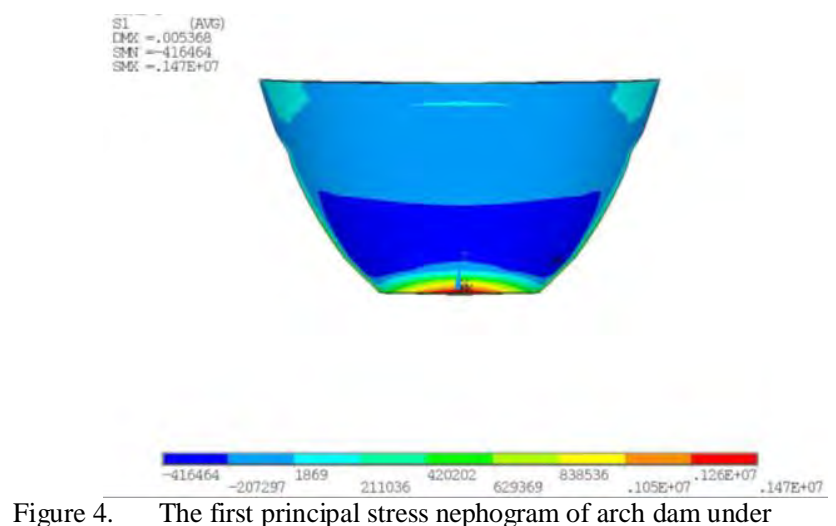
case $2(\mathrm{~Pa})$ level and tail water level; case 4, dead weight and check water level and tail water level and seismic action.

\section{Structure Analysis of Arch Dam}

Stress Analysis. The first principal stress nephogram and circumferential stress nephogram of arch dam under different cases show in Fig .2 and Fig.9.
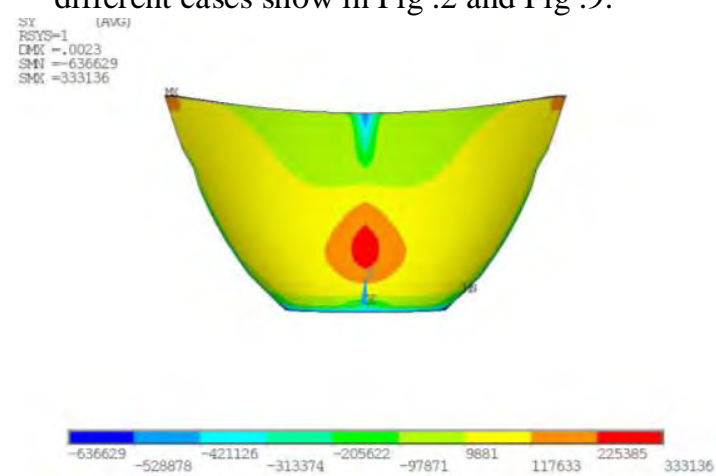

Figure 3. Circumferential stress nephogram of arch dam under case $1(\mathrm{~Pa})$

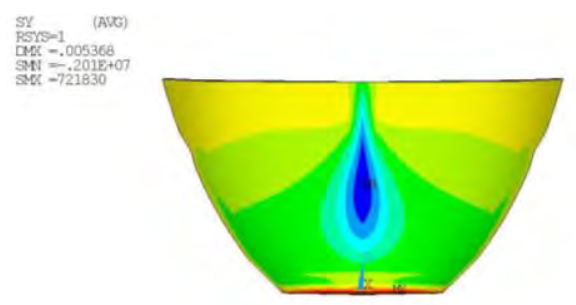

Figure 5. Circumferential stress nephogram of arch dam under case $2(\mathrm{~Pa})$ 


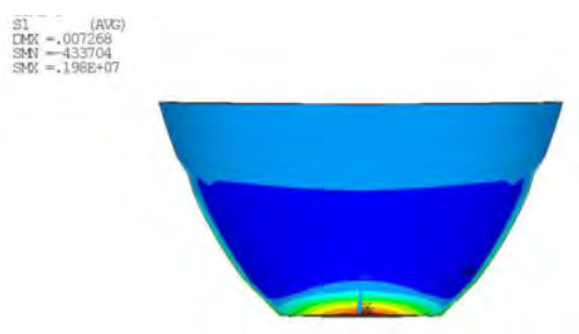

Figure 6. The first principal stress nephogram of arch dam under case $3(\mathrm{~Pa})$

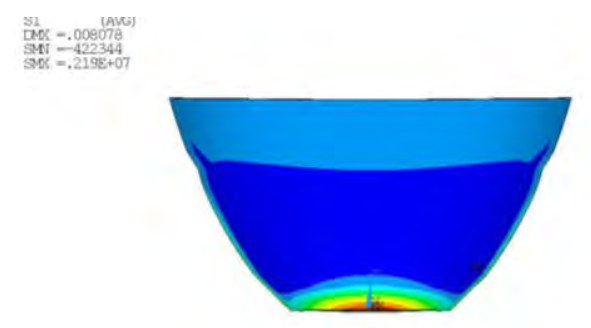

Figure 8. The first principal stress nephogram of arch dam under case $4(\mathrm{~Pa})$

As can be seen from Fig .2 to Fig .9, not only tensile stress but also compressive stress are all symmetric distribution along central axis of the river bed. Except under dead weight, the maximum stress appears in the border of arch dam and bedrock, maximum compressive stress appears in the border of dam's bottom and bedrock. The maximum stress values are local stress concentration, does not affect the safety of the structure. Under the action of dead weight, the maximum tensile stress appears in dam shoulders. Stress concentration at the bottom of dam can be dealt with by using finite

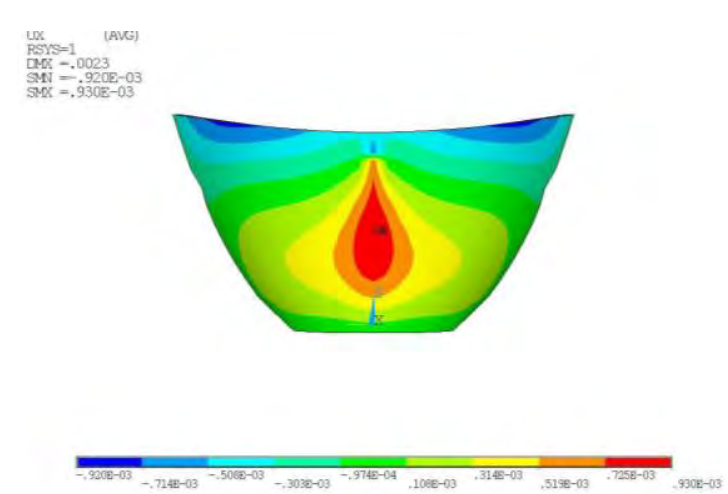

Figure 10. Radial displacement nephogram of arch dam under case $1(\mathrm{~m})$
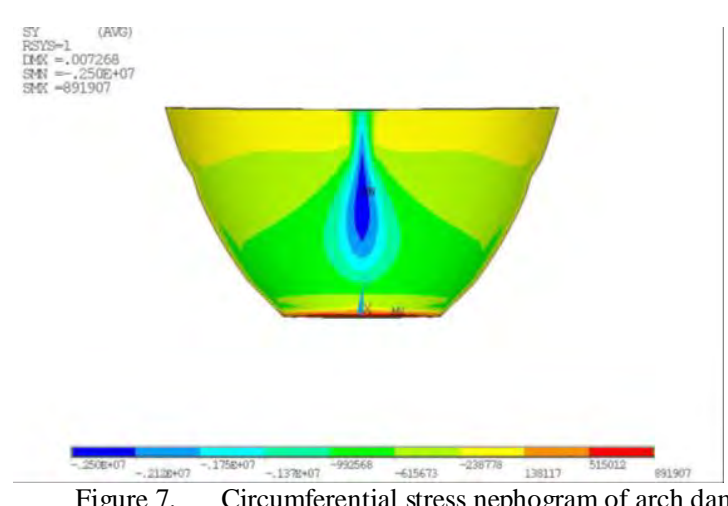

Figure 7. Circumferential stress nephogram of arch dam under case $3(\mathrm{~Pa})$
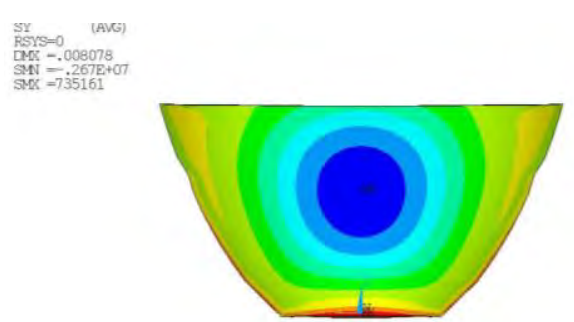

Figure 9. Circumferential stress nephogram of arch dam under case $4(\mathrm{~Pa})$

element equivalent stress method, finite element equivalent stress method can modify finite element calculation results effectively, which is a better solution to the problem of arch dam that stress is too much large on the border[10].

\section{A Deformation Analysis.}

Through deformation analysis of concrete arch dam of Hongyan hydropower station, can gets radial displacement nephogram under different cases, radial displacement nephogram show in Fig .10 and Fig .13
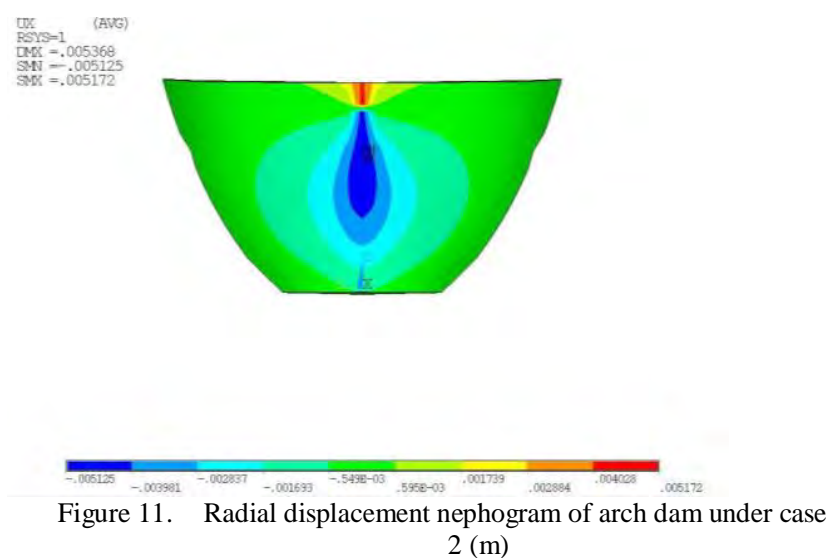

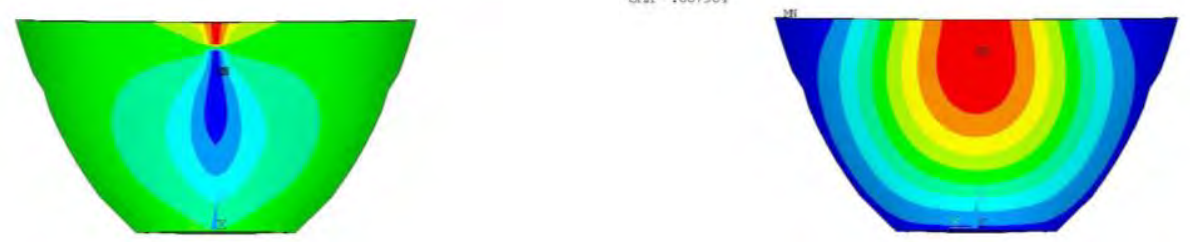

Figure 12. Radial displacement nephogram of arch dam under case $3(\mathrm{~m})$

As can be seen from Fig .10 to t Fig .13, under case 1, maximum radial displacement of arch dam is $0.93 \mathrm{~mm}$; under case 2, maximum radial displacement is $5.17 \mathrm{~mm}$; under case 3, maximum radial displacement is $7.13 \mathrm{~mm}$; under case 4, maximum radial displacement is $7.96 \mathrm{~mm}$. Maximum radial displacement of arch dam under different cases occur at the arch crown, maximum displacement of arch dam increases along with the increase of load. Through case 1 compares with case 2, we can see that water load have larger influence on the displacement. Through case 3 compares with case 4 , influence of seismic action is smaller than influence of water load.

\section{Conclusion}

In conclusion, Hongyan hydropower station adopts concrete arch dam scheme is reasonable. Circumferential stress of arch dam at upstream is compressive stress basically, and the first principal stress of arch dam is small, can satisfy the strength requirement, structure is safe and reliable.

\section{REFERENCES}

[1] Li Shouyi,Ding Lujun,Zhao Lijuan et al. Optimization design of arch dam shape with modified complex method [J]. Advances in Engineering Software,2009,40(9):804-808.

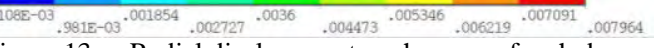

Figure 13. Radial displacement nephogram of arch dam under case $4(\mathrm{~m})$

[2] Seyed Mohammad Seyedpoor,Javad Salajegheh,Eysa Salajegheh et al. Shape optimal design of materially nonlinear arch dams including dam-water-foundation rock interaction using an improved PSO algorithm [J]. Optimization and engineering,2012,13(1):79-100.

[3] Bans Sevim,Alemdar Bayraktar,Ahmet Can Altunisik et al Investigation of water length effects on the modal behavior of a prototype arch dam using operational and analytical moda analyses $[\mathrm{J}]$. Structural engineering and mechanics, 2011,37(6):593-615.

[4] SL191-2008. Design Code for Hydraulic Concrete Structure[S] China Water Conservancy and Hydropower Press, 2008.

[5] Bang-Fuh Chen, Yin-Sen Yuan. Hydrodynamic Pressures on Arch Dam during Earthquakes [J]. Journal of hydraulic engineering,2011,137(1):34-44.

[6] Mingrong Shen, Jianfeng Chen. Rock mechanics [M]. Tongii University Press, 2006.

[7] Bofang Zhu. Finite Element Method Principle and Application [M]. China Water Conservancy and Hydropower Press, 1998.

[8] Wen-ping Fei, Lin Zhang, Ru Zhang et al. Experimental study on a geo-mechanical model of a high arch dam [J]. International Journal of Rock Mechanics and Mining Sciences, 2010, 47(2):299-306.

[9] SL282-2003. Design Code for Concrete Arch Dam [S]. China Water Conservancy and Hydropower Press, 2003.

[10] [10] Bofang Zhu, Jizhang Gao, Zuyu Chen, Yisheng Li. Arch Dam Design and Research [M]. China Water Conservancy and Hydropower Press, 2002 